\title{
Estudio descriptivo de las prácticas de manufactura en la industria panelera de los trapiches San Francisco y La Esmeralda en Boyacá y Caldas.
}

\author{
Lucía Constanza Corrales Ramírez ${ }^{1}$, Maira María Muñoz Ariza ${ }^{2}$, \\ Lina María González Pérez ${ }^{2}$
}

\author{
${ }^{1}$ Docente investigador. Universidad Colegio Mayor de Cundinamarca \\ ${ }^{2}$ Estudiantes Universidad Colegio Mayor de Cundinamarca Bogotá - Colombia
}

Correspondencia: 1corrales@unicolmayor.edu.co

Recibido: 12/07/2012 Aceptado: 13/11/2012

\section{Resumen}

El objetivo de este proyecto fue evaluar la aplicación de las prácticas de manufactura en los trapiches San Francisco y La Esmeralda mediante la aplicación de encuestas etnográficas, documentación fotográfica e identificación de contaminantes microbiológicos presentes en la panela, manos de empleados e implementos de trabajo. En los resultados obtenidos se encontró que una proporción importante de las muestras presentaron contaminación por bacterias como Staphylococcus epidermidis, Streptococcus uberis, Leuconostoc mesenteroides, Bacillus spp, Corynebacterium spp, Actynomices spp, Lactococcus lactis y Gardnerella vaginalis, y hongos como Fusarium spp, Aspergillus spp, Paecilomyces spp, Penicillium spp y Mucor spp, demostrando falencias en el proceso de producción por la falta de implementación de las Buenas Prácticas de Manufactura. A partir del estudio, se recomendó capacitar a los empleados periódicamente acerca de la manipulación de alimentos y prácticas básicas de higiene y realizar una vigilancia más estricta a los trapiches.

Palabras clave: Panela, contaminación microbiológica, Buenas Prácticas de Manufactura.

\section{Descriptive study of manufacturing practices of panela (Brown sugar) industry from the San Francisco and La Esmeralda mills (Boyacá and Caldas, Colombia) Abstract}

In this study was evaluated the implementation of manufacturing practices in the San Francisco and La Esmeralda mills through ethnographic surveys, photographic evidence and recovery of microbiological contaminants from panela, employees hands and working tools. A significant proportion of samples from hands, work tools and panela were found contaminate with bacteria such as Staphylococcus epidermidis, Streptococcus uberis, Leuconostoc mesenteroides, Bacillus, Corynebacterium, Actinomyces spp, Lactococcus lactis and Gardnerella vaginalis, and fungi including Fusarium spp, Aspergillus spp, Paecilomyces spp, Penicillium spp and Mucor spp. These results revealed failures in the production process due to the lack of implementation of Good Manufacturing Practices. Based in this study it was recommended to give regular trainings to the employees about food handling and basic hygiene practices. Also carry out a strict monitoring of the mills in order to be able in the future to rank Colombia as greater panela producer and exporter.

Keywords: Brown sugar, microbiological contamination, Good Manufacturing Practice 


\section{Introducción}

Colombia es un país reconocido por ser el segundo productor mundial de panela después de la India, cuya producción se centra en la región Andina en departamentos como; Boyacá, Antioquia, Cundinamarca, Santander y Caldas (1). La panela además posee un gran impacto tanto económico como sociocultural en Colombia, porque además del consumo ha sido empleada para curación de heridas. Algunas personas, en particular aquellas que habitan el área rural, afirman que este alimento tiene propiedades desinflamatorias y actividad bactericida (2).

La panela es elaborada en un establecimiento denominado trapiche, en donde la actividad principal consiste en la extracción de los jugos de la caña de azúcar para la elaboración de este alimento, siguiendo en teoría un protocolo establecido por FEDEPANELA (Federación Nacional de Productores de Panela) y el Ministerio de Agricultura y Desarrollo Rural bajo la Norma Sanitaria establecida por el INVIMA (Instituto Nacional de Vigilancia de Medicamentos y Alimentos) y el Ministerio de Protección Social (3), implementando las Buenas Prácticas de Manufactura (BPM) para reducir los riesgos de contaminación y ofrecer un alimento sano y apto para el consumo.

Sin embargo, se ha reportado en análisis microbiológicos y físico- químicos, la presencia de ciertos contaminantes de tipo micótico, bacteriano, de metales pesados (plomo y arsénico), de blanqueadores (sulfitos) y colorantes, lo cual, no permite garantizar la calidad suficiente de dicho producto y permite suponer que existen falencias en los procesos de producción y que en un futuro pueden generar problemas de salud a los consumidores por los efectos adversos que generan estos agentes (4).

Las agroindustrias en Colombia son una de las principales fuentes tanto de empleo como de ingresos para la economía nacional. De esta forma, con la firma del Tratado de libre comercio (TLC) con Estados Unidos se desea exportar productos tradicionales, autóctonos y competitivos en el mercado nacional e internacional con el fin de buscar nuevas inversiones en la industria agrícola. Para lo cual la panela debe ser elaborada bajo el cumplimiento de la normativa y protocolos establecidos para su fabricación y contar con la vigilancia de los organismos que hacen parte de la Comisión Nacional Intersectorial para la Vigilancia de la Calidad de la Panela (INVIMA, FEDEPANELA, Ministerio de Agricultura y Desarrollo Rural y el Ministerio de protección social) (5).

Según la FAO, Colombia es considerada como el segundo país productor de panela y el primer consumidor de este. Cada colombiano consume de 31 a $33 \mathrm{~kg}$ anualmente. En el ámbito mundial la panela es elaborada por diversos países pero han sido pocos los estudios realizados en la agroindustria panelera. Realizar la caracterización microbiológica de este alimento permitirá conocer algunas de las falencias que se presentan en su proceso de producción y las fuentes de contaminación que se deberán intervenir para reducirla (6).

\section{Materiales y métodos}

Primera fase: Sensibilización. Con autorización de los administradores de los trapiches se realizó un reconocimiento de las áreas en las que se realiza el proceso de producción de la panela, los cultivos de caña de azúcar y sus alrededores. En este reconocimiento se obtuvo material fotográfico como soporte y se realizó una sensibilización, mediante una breve explicación sobre el estudio y los diferentes aspectos involucrados en las BPM.

Aplicación de encuesta diagnóstica y etnográfica. Se realizó una encuesta diagnóstica a los trabajadores de los trapiches con el objetivo de indagar sobre el nivel de conocimiento que manejan acerca de las BPM, manipulación de alimentos, normativa y medidas de seguridad en la industria panelera. De igual forma, se les aplicó una encuesta etnográfica con el fin de conocer su grado de escolaridad y el tiempo de vinculación a esta labor. 
Segunda Fase. Toma de muestras. La toma de muestra se dividió en: toma de muestras de lotes de panela, de frotis de manos a los trabajadores y de frotis a los implementos de trabajo.

La toma de muestras de panela se realizó a diez lotes escogidos al azar, luego de su moldeo y enfriamiento. De cada lote se tomaron muestras por duplicado depositadas en bolsas plásticas con cierre hermético, usando las barreras de bioseguridad necesarias para proteger el producto. Las muestras fueron identificadas con el número del lote correspondiente.

La toma de muestra de manos se realizó de la siguiente forma: trapiche San Francisco; a diez empleados escogidos al azar y en el trapiche La Esmeralda a cinco trabajadores, que corresponde a la totalidad de empleados que laboran en este lugar. La metodología incluyó frotis de manos específicamente de las uñas y de la zona interdigital mediante escobillones estériles humedecidos con solución salina. De igual forma, se indagó y revisó si los trabajadores presentaban alguna lesión en piel o uñas con el fin de realizar el frotis de este lugar. Los escobillones fueron depositados en medios de transporte Stuart a temperatura de refrigeración.

La toma de muestra en los utensilios de trabajo se realizó en utensilios escogidos aleatoriamente y se implementó el mismo procedimiento que en caso de las manos. En el trapiche San Francisco se escogieron diez implementos y en el trapiche La Esmeralda se escogieron doce.

Análisis microbiológico. La metodología implementada para esta investigación fue; (i) La descrita en el Manual de Microbiología Food and Drug Administration, (ii) El Protocolo de Conservación de Muestras de Panela del estudio de Rubio y Garay (2012), (iii) El Protocolo de Toma de Muestras a Manos de Manipuladores de Alimentos del estudio de la Gobernación del Atlántico modificado por las autoras (7).
Las muestras transportadas en el medio Stuart con los escobillones a partir de frotis de manos y de implementos de trabajo se sembraron en agar sangre, agar Mc Conkey, agar ENDO, agar Saboreaud y agar YGC.

Cultivo de las muestras de panela. Incluyó los siguientes procedimientos: (i) dilución de cada una de las muestras en $9.0 \mathrm{~mL}$ de agua peptonada estéril, para este proceso se utilizaron 2.0 gramos de panela y se depositaron en los tubos de agua peptonada según el número de la muestra, (ii) se procedió a homogenizar las muestras y se dejaron durante 24 horas a temperatura ambiente, con el fin de lograr completa disolución de la muestra, (iii) al día siguiente, se hicieron tres diluciones seriadas decimales de las muestras en base 10, las cuales se homogenizaron y se dejaron 24 horas a temperatura ambiente.

A continuación, se realizó la siembra del tubo inicial y las tres diluciones decimales de las muestras de panela en los medios en placa de agar sangre, agar Mc Conkey, agar ENDO, agar Saboreaud y agar YGC. De igual forma estas diluciones se sembraron en caldo verde bilis brillante, para detectar la presencia de coliformes. A todas las unidades formadoras de colonias detectadas en los medios de cultivo se les realizó aislamiento para obtener las cepas puras.

Al mismo tiempo, se realizó coloración de Gram de esas muestras. A aquellas muestras que presentaron bacterias esporuladas; se les realizó coloración de Shaeffer Foulton y para la identificación bioquímica de los microorganismos se utilizó el método semiautomatizado BBL Crystal.

Por último, a las unidades formadoras de colonia que crecieron en los medios de cultivo Saboreaud y YGC para su identificación se les realizó lectura de las características macroscópicas y microscópicas con azul de lactofenol. 


\section{Resultados}

Encuestas etnográficas. Se encontró que un 100\% de la población entrevistada, en los dos trapiches, es rural; con un $92 \%$ de trabajadores mayores de edad en el trapiche San Francisco y un 60\% en el trapiche La Esmeralda.

Con relación al grado de escolaridad de los empleados se encontró que en el trapiche San Francisco solamente el 25\% terminaron el bachillerato, $42 \%$ tienen estudios de educación básica incompleta, $17 \%$ finalizaron sus estudios de educación primaria y un $16 \%$ no terminaron sus estudios primarios.

En el trapiche La Esmeralda ninguno de los empleados terminó sus estudios de bachillerato; un $80 \%$ realizaron estudios de educación básica primaria completa y un $20 \%$ no finalizaron su educación primaria. Es importante tener en cuenta que ninguno de los trabajadores de los trapiches presenta ningún tipo de estudio técnico.

De igual forma, se indagó en los trabajadores el tiempo de experiencia laboral en la actividad panelera. En el trapiche San Francisco; un 60\% los trabajadores poseen más de 10 años de experiencia en este oficio, y en el trapiche La Esmeralda solamente el $40 \%$ poseen una experiencia laboral de más de diez años.

Los trabajadores manifestaron que conocen los procesos de producción de la panela porque es una actividad tradicional familiar, principalmente a cargo de los hombres. En el trapiche San Francisco se encuentran tres empleadas, dos de las cuales se encargan de la preparación de los alimentos y una tercera que realiza el empaque de la panela.

\section{Encuestas diagnósticas}

En las encuestas diagnósticas se indagó acerca del conocimiento que poseen los trabajadores acerca de ¿Qué son?, ¿En qué consisten? y ¿Cómo se aplican las BPM?, al igual de las normas que rigen y controlan la industria panelera. También se indagó sobre ciertos aspectos particulares de los trapiches. En el trapiche San Francisco un 60\% de los trabajadores encuestados y en el trapiche La Esmeralda un $80 \%$ manifestaron no tener conocimiento relacionado con respecto a las BPM.

En cuanto al conocimiento sobre la normativa que rige y controla la agroindustria panelera se encontró; en el trapiche San Francisco un 50\% dicen conocerlas y en el trapiche La Esmeralda tan solo un $20 \%$. Sin embargo, al preguntarles cuáles eran las normas que conocían, se refirieron al ítem de la norma relacionado con la aplicación de químicos a la panela.

En lo relacionado con la formación en manipulación de alimentos y cursos de actualización, el resultado fue el siguiente; en el molino San Francisco el 8\% y en el trapiche La Esmeralda el 20\% que manifiestan haber recibido capacitación.

Así mismo, se interroga al personal que labora en los dos trapiches sobre las barreras de bioseguridad que utilizan al momento de manipular la panela. Al respecto manifiestan usar gorro, tapabocas y botas. No obstante, al momento de hacer la observación, es evidente que solamente de estas barreras usan las botas.

Con respecto a las prácticas higiénicas sanitarias empleadas en los trapiches, el $100 \%$ de los trabajadores de los dos trapiches manifiestan lavar sus manos antes, durante y después de su actividad laboral. Sin embargo, al preguntar cómo realizan dicho lavado, indican que solamente lo realizan con agua. A pesar de que refieren conocer que dentro del trapiche y en su trabajo deben efectuar practicas higiénico sanitarias adecuadas de limpieza y manipulación de alimentos para garantizar un producto seguro para el consumidor. Sin embargo, manifiestan que los trapiches no cumplen con una infraestructura adecuada, no existen implementación de normas BPM, protocolo de procedimientos y tampoco se preocupan por ofrecer cursos de actualización en manejo de alimentos. De igual forma informaron que les gustaría formarse en es- 
tos aspectos, pues consideran importante aprender un poco más sobre la labor que realizan.

Comparación de los aspectos a evaluar por las BPM en los trapiches.

Con relación a la aplicación de las BPM, los trapiches pasan por alto muchos aspectos en especial aquellos que se refieren al impacto ambiental, infraestructura y aplicación de normas higiénico sanitarias. Dentro de la evaluación de las Buenas Prácticas de Manufactura que emplean estos trapiches, se estudiaron los siguientes ítems:

1. Impacto ambiental: tala de árboles, vertimientos, emisiones de la hornilla.

2. Recursos naturales: cultivos de caña de azúcar, recursos tecnológicos, producción y aprovechamiento de la cachaza, uso de adulterantes químicos.

3. Instalaciones físicas de los trapiches: división de áreas de producción, vías de acceso, servicios públicos, infraestructura, control de plagas.

4. Proceso de producción: prelimpieza, clarificación de los jugos, calentamiento de jugos, moldeo y enfriamiento de la panela, empaque de la panela.

5. Personal: capacitaciones.

6. Manipulación de alimentos: medidas de bioseguridad, procesos de higiene.

7. Trapiches y alrededores: descarte y eliminación de residuos, cría de animales, actividades agropecuarias.

8. Manejo higiénico del trapiche: limpieza del establecimiento, lavado de utensilios, actividades aledañas al trapiche.

9. Manejo y mantenimiento de equipos: manipulación de los equipos, mantenimiento periódico de la maquinaria.

Impacto ambiental. Tala de árboles. En el trapiche San Francisco; los cultivos de cańa de azúcar son plantados en zonas que eran áreas arborizadas o donde ya existían plantaciones. Luego de realizar la cosecha de la caña, los restos de esta son quemados causando así erosión del suelo.

En el trapiche La Esmeralda, sus plantaciones siempre están en los mismos terrenos pues consideran pertinente mantener un equilibrio ambiental. Razón por la cual, siempre arrancan de raíz aquellos sobrantes del cultivo, y luego los dejan en una zona aledańa del trapiche para su degradación. Abonan la tierra y siembran de nuevo caña de azúcar. Sin embargo, este trapiche realiza tala de árboles porque el horno funciona con leńa.

Vertimientos. En los dos trapiches el tratamiento que se le da a los afluentes generados en el trapiche son insuficientes. Por ejemplo, el agua de las gaveras solamente es cambiada en el momento en que el trabajador encargado de la zona de moldeo de la panela lo considera pertinente, pasando así días enteros el agua de lavado de gaveras y utensilios en la batea sin ser renovada. El lavado de los prelimpiadores es realizado una vez por semana.

Emisiones. El trapiche San Francisco posee una hornilla que funciona con bagazo verde, lo cual genera combustiones completas, que contribuye a la conservación del medio ambiente. En el trapiche La Esmeralda poseen una hornilla que funciona con leña, que puede llegar a generar combustiones incompletas con posibles emisiones de gases tóxicos.

Recursos Naturales. Cultivos de caña de azúcar. En los trapiches estudiados, los cultivos de cańa son plantados sin recibir ningún tipo de asesoría (no se usa ningún tipo de sistema de siembra) y no se tiene en cuenta el efecto protector que pueden generar estos al suelo para evitar su erosión.

Recursos tecnológicos. El trapiche San Francisco así como el trapiche La Esmeralda poseen una hornilla tradicional.

Producción y aprovechamiento de la cachaza. en el trapiche San Francisco realizan aprovechamiento 
de la cachaza destinándola para la alimentación de los animales además, de venderla a las fincas aledañas. En La Esmeralda descartan la cachaza y no le dan otro uso.

Uso de adulterantes quimicos. En el trapiche San Francisco en ocasiones usan clarol para mejorar el aspecto de la panela por orden de la empresa contratante. En La Esmeralda no usan dentro de sus procesos de producción ningún adulterante químico.

\section{Instalaciones físicas de los trapiches}

División áreas de producción. Ninguno de los trapiches posee división de las zonas de procesamiento (área de batido, moldeo y empaque de la panela).

Vías de acceso. Ninguno de los trapiches posee vías de acceso adecuadas, debido a que son destapadas y en el caso del trapiche La Esmeralda son demasiado estrechadas, en época de lluvias son de difícil acceso.

El trapiche San Francisco está ubicado aproximadamente a 15 minutos en vehículo de una vía principal. El trapiche La Esmeralda se encuentra ubicado a 40 minutos de la vía principal caminando (porque no hay acceso para vehículos).

Servicios públicos. Los dos trapiches cuentan con energía eléctrica, agua y alcantarillado. En el molino San Francisco además cuentan con gas natural.

Infraestructura. El trapiche San Francisco posee techo en tejas de eternit, columnas hechas de concreto y ladrillo y unas pocas de troncos de árbol, deficiente sistema de iluminación, pisos en obra negra, solamente en el área de moldeo se encuentra paredes con baldosa. Los techos, paredes y columnas se encuentran sucios y cubiertos por telarañas. No existen programas de aseo y limpieza en el trapiche. Las áreas de descanso e higiene de los empleados se encuentran dentro del trapiche y cuentan con un lavamanos a las afueras de la zona de moldeo que no es usado por los empleados, ya que prefieren usar para su lavado de manos la batea donde se lavan las gaveras.

El trapiche La Esmeralda posee un techo de tejas de zinc, simulación de columnas con troncos de árbol y no posee ninguna pared, por lo cual todas las áreas de producción y procesamiento de la panela se encuentran al aire libre. Iluminación deficiente, sus pisos se encuentran en obra negra, la zona de descanso e higiene de los empleados se encuentra ubicada al lado del trapiche y no poseen un lavamanos o sanitario, cercano al trapiche.

Control de Plagas. En ninguno de los trapiches estudiados realizan control de roedores y anfibios.

\section{Procesos de producción}

Prelimpieza. La prelimpieza de los jugos, el material flotante y el decantado en el prelimpiador son retirados de manera periódica, una vez por semana.

Clarificación de jugos. En el trapiche San Francisco, en la clarificación se retira la cachaza y se deposita en bateas para la alimentación de los animales, ya que esta posee un alto valor energético por su gran contenido de sacarosa. En La Esmeralda, en la clarificación no se retira ni reutiliza la cachaza. En San Francisco, en ocasiones se usa clarol para regular el color de la panela, dependiendo de las exigencias en cuanto al color del producto por parte del contratista. En La Esmeralda no se utiliza ningún tipo de blanquemiento. Dentro de los aglutinantes utilizados para limpiar el jugo de la caña de azúcar, ambos trapiches en estudio se usa la planta balso (Heliocarpus americanus), y cal para regular el $\mathrm{pH}$ del producto.

Calentamiento de jugos. En los dos trapiches estudiados los jugos pasan por tres fondos de aluminio en donde se calientan para extraer aproximadamente el $90 \%$ del agua que contiene.

Moldeo y enfriamiento de la panela. En el trapiche San Francisco la panela es moldeada en una mesa recubierta por un costal en fique y es colocada a 
enfriar en el suelo. En el trapiche la Esmeralda, la panela es moldeada sobre una mesa que se encuentra expuesta al aire libre y en el mismo lugar se realiza el enfriamiento.

Empaque de la panela. En el trapiche San Francisco, la panela es envuelta en papel vinipel con etiqueta pero sin código de barras y luego colocada en cajas de cartón marcadas con el logo y nombre del trapiche. En el trapiche La Esmeralda la panela es colocada en cajas de cartón sin ningún tipo de identificación.

Almacenamiento de la panela. En San Francisco, la panela es almacenada en una bodega durante aproximadamente una semana mientras es comercializada. En La Esmeralda, la panela no es almacenada, es entregada a los comercializadores del producto.

\section{Personal}

Capacitaciones. El personal de los trapiches evaluados no se encuentra informado ni capacitado frente a los tipos de contaminación microbiológica que puede presentar el alimento, y las fuentes de contaminación como: lesiones abiertas, nacidos, llagas, heridas infectadas, etc.

\section{Manipulación de alimentos}

Medidas de bioseguridad. En los dos trapiches, los empleados no conocen las medidas de bioseguridad que deben tomar para manipular los alimentos con protección del producto, el ambiente y de ellos mismos. Como por ejemplo: cubrir las heridas, lavarse bien las manos y desinfectarlas, mantener la higiene personal, no usar prendas inseguras que puedan caer en pailas o bateas, remover las joyas de las manos, utilizar tapabocas, gorro, delantal, guantes, no comer, beber y fumar en las zonas de producción de la panela, utilizar calzado con suela antideslizante.

Procesos de higiene. La totalidad de los empleados de los trapiches estudiados realizan constantemente lavado de manos pero solamente con agua, en especial con la que lavan las gaveras.

\section{Trapiches y sus alrededores}

Descarte y eliminación de residuos. Ninguno de los dos trapiches posee procedimientos de descarte y eliminación de residuos. En el caso del bagazo que sobra luego de la extracción del jugo de la caña de azúcar; en el trapiche San Francisco se aprovecha para el funcionamiento de la hornilla y para la generación de abonos. Sin embargo, la zona de almacenamiento de este no está separada de las demás áreas de producción de la panela. En el caso del trapiche La Esmeralda no se realiza aprovechamiento del bagazo y no se almacena en un sitio adecuado sino que por el contrario se puede encontrar en cualquier parte de los alrededores del trapiche.

Cría de animales. En el trapiche San Francisco usan animales para el transporte de la cańa y su zona de descargue está en el mismo lugar donde se realiza el procesamiento de la caña. En La Esmeralda como sus cultivos se encuentran muy cerca de la zona de producción de panela no se utilizan animales para el traslado de la materia prima. Además, en ambos trapiches la zona de procesamiento de caña de azúcar, de jugos y moldeo de la panela cuenta con el transito permanente de animales (perros, gallinas, patos, gansos, burros, etc).

Actividades agropecuarias. De los trapiches estudiados, el trapiche San Francisco realiza otro tipo de actividades diferentes a la producción de panela; cría de animales (perros, gatos, gallinas, pollos, patos, gansos, cerdos, vacas, caballos), producción de café y producción de abonos.

\section{Manejo higiénico del trapiche}

Limpieza del establecimiento. Ninguno de los trapiches estudiados posee programas de aseo y limpieza de su infraestructura.

Lavado de utensilios. En ambos trapiches, los utensilios son lavados con el agua de las bateas que generalmente llevan varios días en este recipiente sin ser renovadas. 
Actividades aledañas al trapiche. En zonas aledañas al trapiche San Francisco utilizan productos de abono no recomendables y hay presencia de moscas, en especial en las zonas de limpieza de los jugos y moldeo de la panela. En el trapiche La Esmeralda se encuentra gran cantidad de abejas que en ocasiones aparecen en el producto terminado.

\section{Manejo y mantenimiento de equipos}

Manipulación de equipos. El trapiche San Francisco posee un molino que en ocasiones no es manejado adecuadamente ya que es forzado a procesar una mayor cantidad de cańa de azúcar de la que tiene capacidad. La Esmeralda posee un molino de buena capacidad.

Mantenimiento periódico de la maquinaria. En los dos trapiches, la hornilla, molino y fondos, no tienen un mantenimiento periódico sino solamente en aquellos casos en que presenten algún daño.

\section{Estudio microbiológico}

El análisis microbiológico evalúa de manera indirecta la práctica higiénica sanitaria. En este se observa que una gran proporción de las muestras analizadas presentaron contaminación microbiana: en el trapiche San Francisco un 60\% presentan contaminación con bacterias y hongos, mientras que en el trapiche La Esmeralda el 46\% de las muestras. Con relación al tipo de contaminación que presentan las muestras, se observa lo siguiente: trapiche San Francisco del 60\% de muestras que presentan contaminación; el 38\% es por bacterias y el $22 \%$ es por hongos. En el trapiche la Esmeralda del 46\% de las muestras contaminadas; el 24\% presenta contaminación por hongos y el $22 \%$ por bacterias, Tablas 1 y 2 . Figuras 1-11.

Tabla 1. Microorganismos obtenidos en el análisis microbiológico, Trapiche San Francisco.

\begin{tabular}{|c|c|c|c|}
\hline \multicolumn{4}{|c|}{ San Francisco } \\
\hline Hongos & Lugar & Bacterias & Lugar \\
\hline Aspergillus spp & Panela & Bacillus brevis & Panela \\
\hline Paecilomyces spp & Panela & Bacillus subtilis & Manos \\
\hline Mucor spp. & Panela & Streptococcus uberis & Batea \\
\hline \multirow[t]{7}{*}{ Levaduras } & Panela & $\begin{array}{l}\text { Lactococcus lactis spp cremoris grupo } N \\
\text { lancefield }\end{array}$ & Manos \\
\hline & & Staphylococcus epidermidis & Manos \\
\hline & & Gardnerella vaginalis & Panela \\
\hline & & Bacillus megaterium & Manos \\
\hline & & Corynebacterium spp & Panela \\
\hline & & Actinomyces spp & Panela \\
\hline & & Bacillus cereus. & Manos \\
\hline
\end{tabular}

Tabla 2. Microorganismos obtenidos en el análisis microbiológico y sus sitios de hallazgo, Trapiche La Esmeralda.

\begin{tabular}{llll} 
& & La Esmeralda & \\
\hline \multicolumn{1}{c}{ Hongos } & \multicolumn{1}{c}{ Lugar } & \multicolumn{1}{c}{ Bacterias } & Lugar \\
\hline Fusarium spp & Panela & Bacillus sphaericus & Panela \\
Penicillium spp & Panela & Bacillus licheniformis & Panela \\
Aspergillus spp & Panela & $\begin{array}{l}\text { Leuconostoc mesenteroides spp mesen- } \\
\text { teroides }\end{array}$ & Panela \\
Levaduras & Panela & Bacillus megaterium & Panela \\
& & Bacillus cereus & Panela \\
& & Staphylococcus epidermidis & Panela \\
& & Gardnerella vaginalis & Panela \\
\hline
\end{tabular}




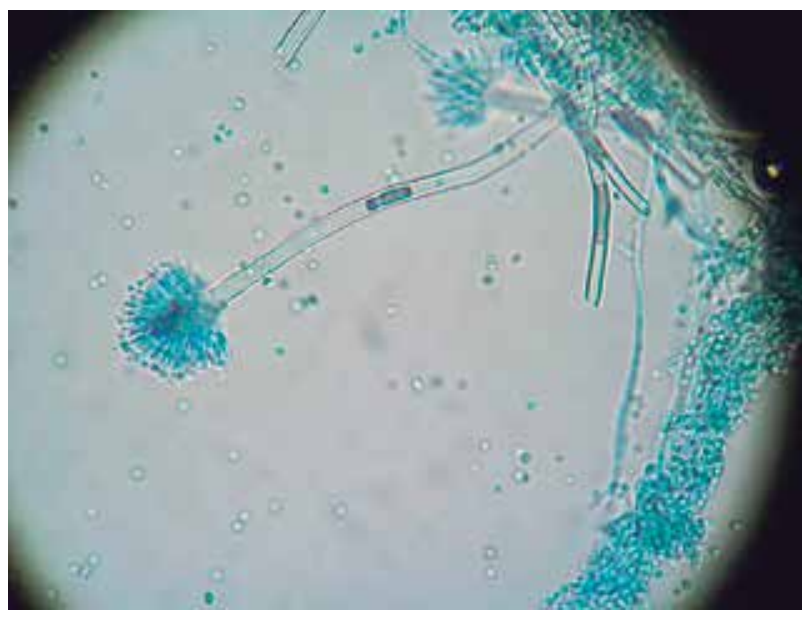

Figura 1. Aspergillus spp.

Observación microscópica con objetivo de 40x.

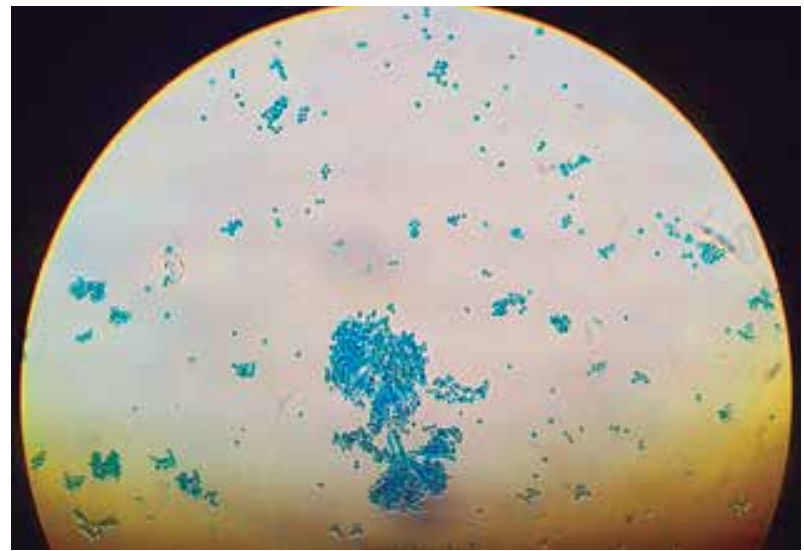

Figura 2. Penicillium spp.

Observación macroscópica y microscópica con objetivo de 40x.

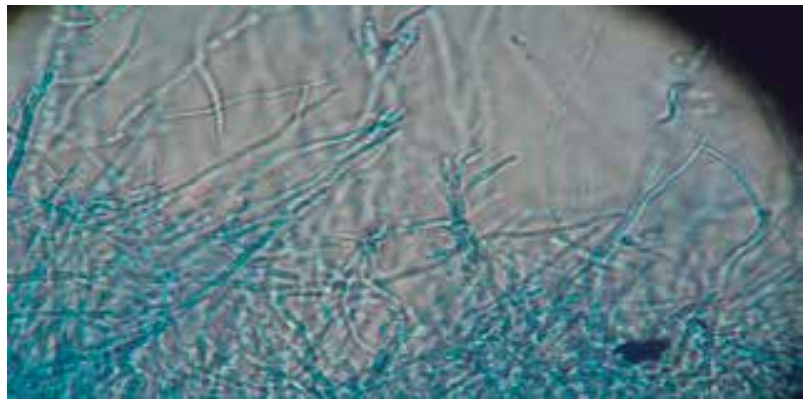

Figura 3. Paecilomyces spp.

Observación macroscópica y microscópica con objetivo de 40x.

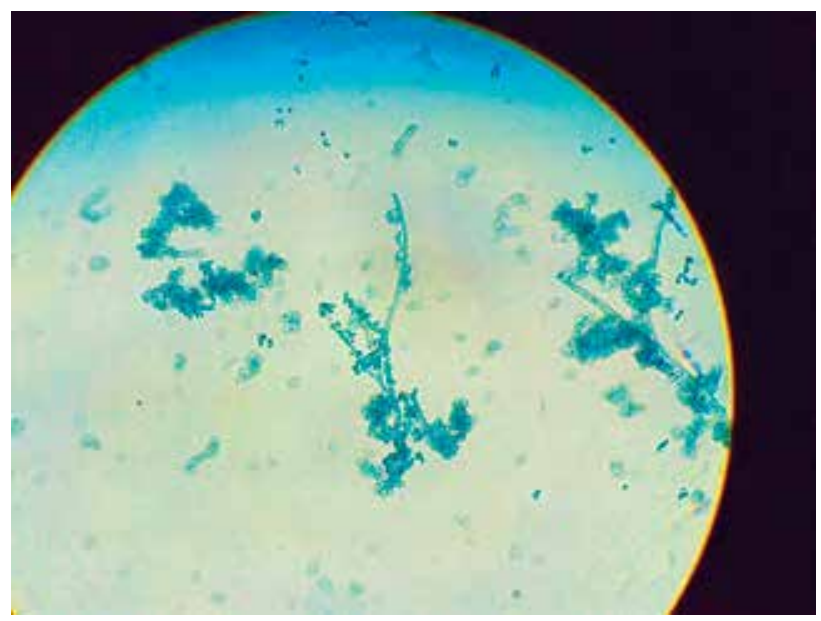

Figura 4. Fusarium spp.

Observación microscópica con objetivo de 40x.

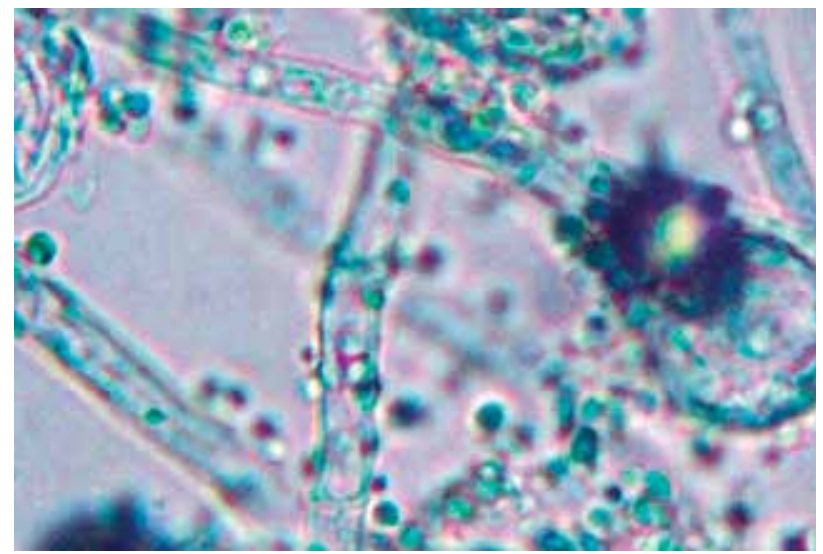

Figura 5. Mucor spp.

Observación microscópica con objetivo de 40x.

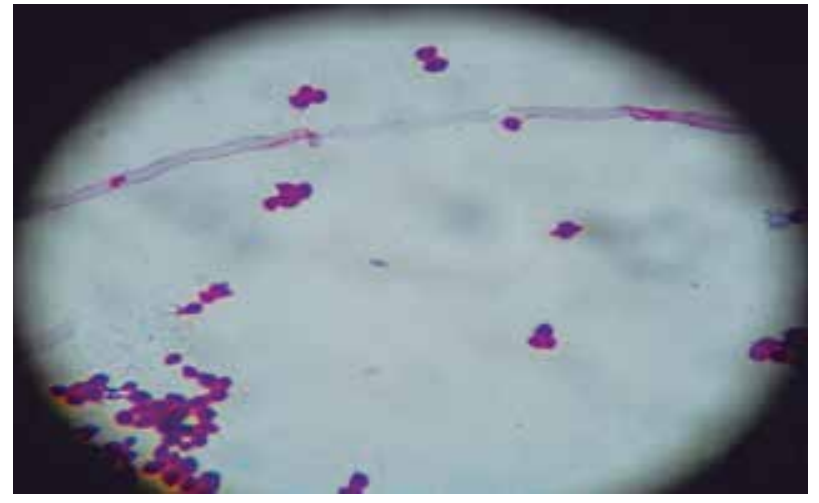

Figura 6. Levaduras. Observación microscópica con objetivo de $40 x$. 


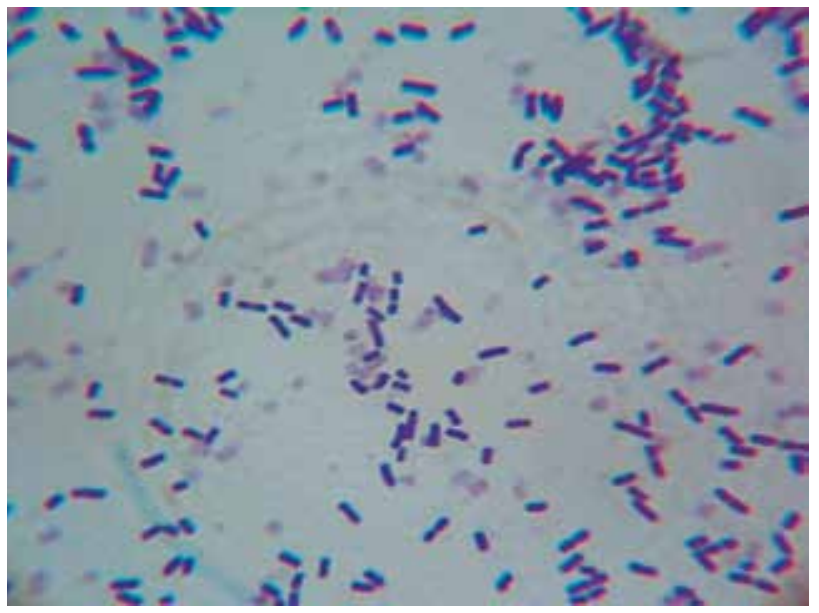

Figura 7. Gardnerella vaginalis. Observación microscópica con objetivo de 40x.

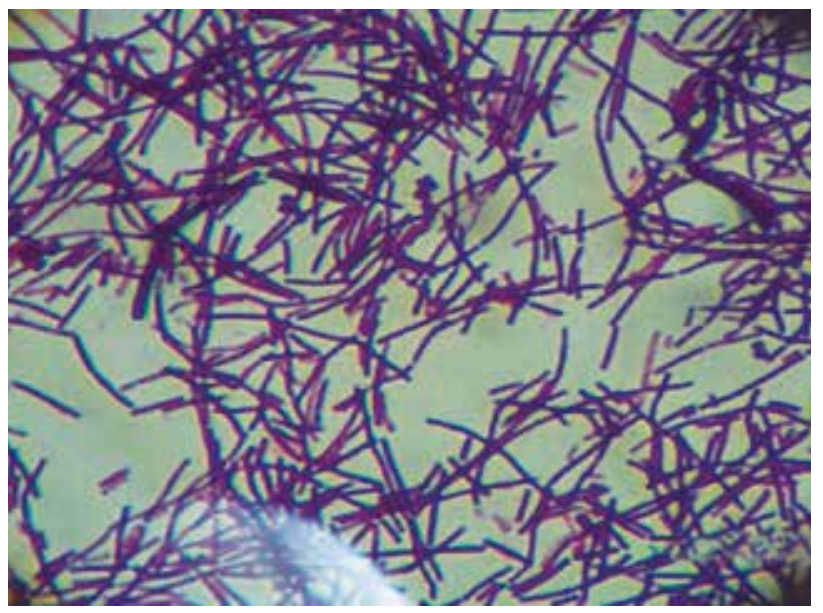

Figura 8. Actinomyces spp. Observación microscópica con objetivo de $40 x$.

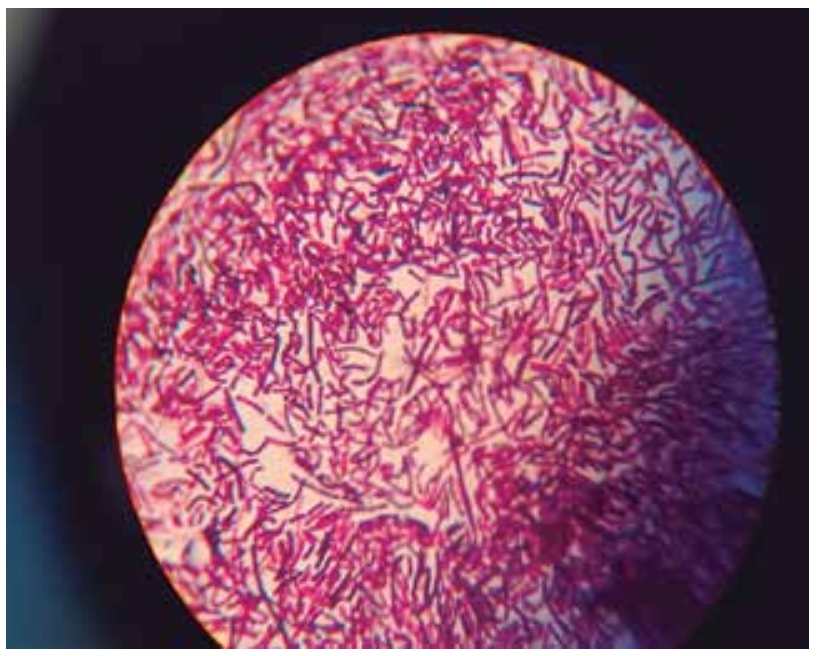

Figura 9. Bacillus $s p p$. Observación macroscópica y microscópica con objetivo de 40x.

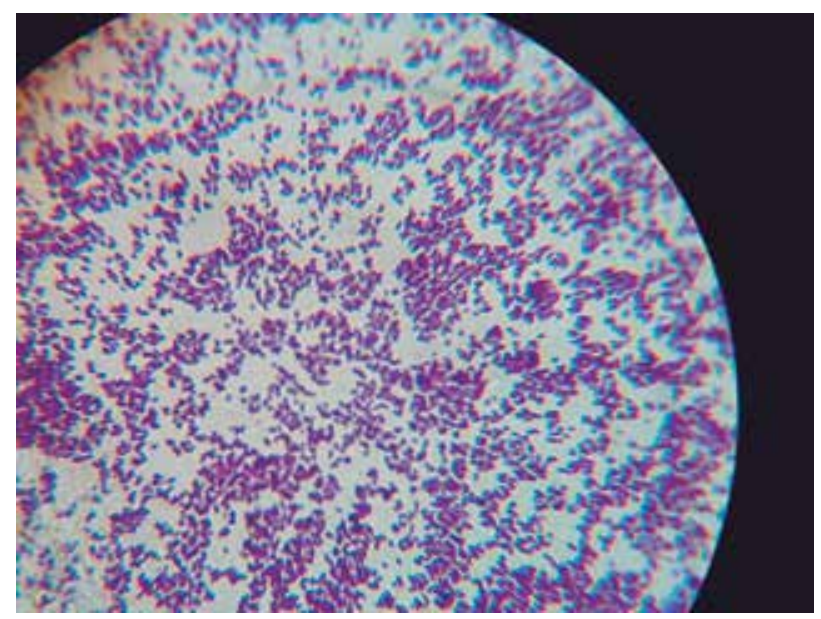

Figura 10. Leuconostoc mesenteroides. Observación microscópica con objetivo de 40x.

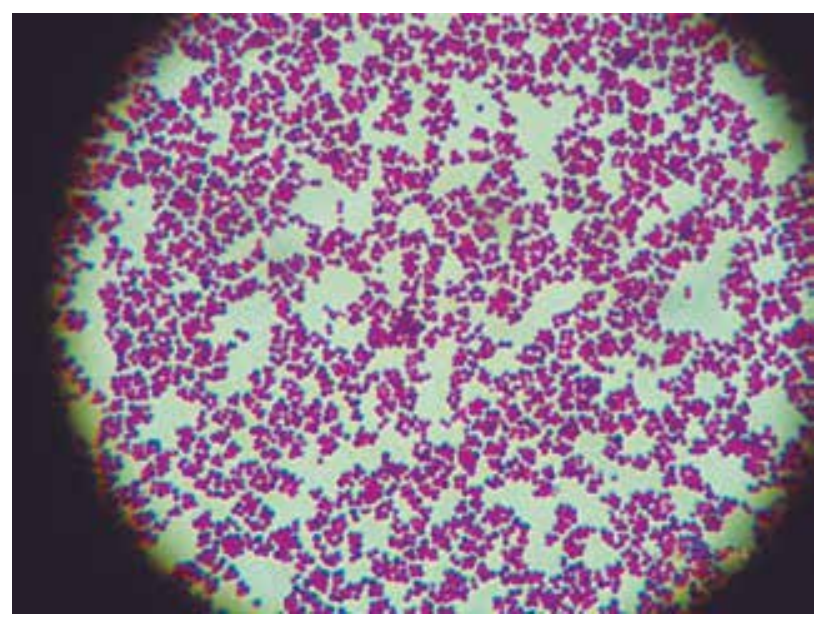

Figura 11. Lactococcus lactis. Observación microscópica con objetivo de 40x.

\section{Discusión}

La industria panelera desde siempre ha sido una actividad que involucra a las personas del área rural, en donde principalmente predomina la tradición familiar y los conocimientos empíricos. En el estudio realizado se observó que para el desempeño de este oficio no es necesario contar con formación técnica adecuada, ni capacitación por parte de entes reguladores en lo relacionado con la fabricación y manipulación de alimento.

En las encuestas realizadas, los trabajadores manifiestan haber vivido siempre en estas veredas y dedicarse a esta actividad industrial por enseñanza de sus padres y familiares. Debido a esto, desde 
muy jóvenes se han visto involucrados en la elaboración de panela. Algunos de los trabajadores cuentan con una experiencia laboral de casi 50 años e incluso se encontró personas menores de edad laborando en este lugar sin haber terminado sus estudios escolares. Los empleados de los trapiches no tienen una formación adecuada para manipular alimentos, lo cual representa un riesgo frente a la calidad y seguridad del alimento para su consumo, así como también de la bioseguridad del empleado.

De igual forma, en las encuestas etnográficas se encontró que los trabajadores de los trapiches manifiestan; no conocer ¿Qué son?, ¿En qué consisten? y ¿Cómo se implementan adecuadamente las BPM?, situación que permite concluir que los trapiches en especial aquellos artesanales están omitiendo los protocolos de procedimientos establecidos por los entes reguladores para la elaboración de alimentos que garanticen la calidad e inocuidad del producto. Así mismo, se evidencia la falta de control por parte de organismos como el INVIMA.

Respecto a las BPM, se encontraron fallas en los procesos de producción de la panela. En primer lugar, es importante resaltar el daño ambiental, debido a la tala de árboles. Así mismo, el equilibrio ambiental se está viendo alterado por actividades como la erosión del suelo, al realizar la quema de los sobrantes de la cosecha, por la inadecuada eliminación de residuos como la cachaza y por el uso de productos y fertilizantes inapropiados.

Aunque las BPM establecen que los prelimpiadores se deben lavar cada doce horas con abundante agua con el fin de eliminar toda la materia orgánica contenida (8), y así reducir al mínimo la contaminación en la panela, este procedimiento no lo realiza ninguno de los trapiches en estudio, generando así riesgos de contaminación en el alimento.

Por otra parte, la industria panelera ha sido generadora de múltiples tipos de contaminación al ambiente, no solamente con relación al agua, sino también al realizar combustiones incompletas en las hornillas que pueden generar gases tóxicos debido al uso de materiales inadecuados para su funcionamiento. Sin embargo, en el trapiche San Francisco implementan para el funcionamiento de su hornilla el bagazo verde, lo cual contribuye al mantenimiento del equilibrio ambiental.

De igual forma, se están desaprovechando los beneficios que aportan los cultivos de cańa para proteger los suelos, debido a que en ninguno de los trapiches recibe asesoría al momento de realizar el sembrado y no hay un sistema de sembrado tecnificado establecido.

En la actividad panelera es importante resaltar que varios de sus residuos pueden reutilizarse; como es el caso de la cachaza, la cual tiene un alto contenido energético que puede ser comercializada como alimento para la cría de animales y generar ingresos adicionales a los trapiches. Sin embargo, en los trapiches en estudio, esta posibilidad no es aprovechada y en cambio es descartada inadecuadamente generando foco de moscas.

Así mismo, la panela, por ser un producto natural, no debe contener ningún tipo de aditivo químico para preservar sus propiedades alimentarias y para que sea un producto seguro para el consumidor. No obstante, algunos contratistas de los molinos solicitan se le adicione clarol para mejorar el color de la panela, el cual es un blanqueador con efectos cancerígenos.

Es importante tener en cuenta que los trapiches deben contar con una infraestructura adecuada; vías de acceso pavimentadas, amplias y seguras; para así evitar desde un comienzo la contaminación de la materia prima. Contar con áreas de trabajo divididas y debidamente señalizadas; para facilitar el procesamiento de la panela y disminuir al mínimo el riesgo de contaminación del producto. Igualmente, debe tener un buen sistema de iluminación y su estructura a base de materiales adecuados y resistentes; incluido el piso que debe ser en baldosa 
para facilitar su limpieza y desinfección. De igual forma, las áreas de descanso y de higiene de los empleados deben estar ubicadas en lugares distantes del trapiche y contar con un lugar de lavado de manos cerca de las áreas de trabajo que permita a los empleados el lavado continuo de sus manos y evitar así contaminar el producto. Es importante que estos establecimientos cuenten con un programa de control de plagas y roedores para garantizar la salubridad e higiene del alimento. Según lo observado en la investigación, ninguno de los trapiches cuenta con lo anteriormente mencionado, generándose así posible contaminación en la panela.

Por otro lado, en la clarificación de los jugos se utilizan aglutinantes naturales denominados mucílagos (sustancias extraídas de los tallos, hojas, frutos y raíces de algunas plantas), que se encargan de aglutinar las impurezas del jugo de la caña de azúcar y eliminar los sólidos en suspensión de este. Dentro de la industria panelera se pueden usar varios mucílagos, pero el más conocido es el Heliocarpus americanus, o más conocido como balso, el cual es utilizado por los trapiches estudiados. Sin embargo, debido al uso irracional por parte de la actividad panelera este tipo de mucílagos se encuentran agotados en todo el territorio colombiano (8).

Una etapa primordial en la producción de panela es el empaque, ya que puede proporcionar condiciones propicias para el crecimiento de hongos y levaduras que deterioran el alimento, esto como consecuencia al uso de materiales inadecuados como hojas de caña y bolsas de papel y/o a no permitir el enfriamiento de la panela antes de ser empacada, lo que genera mayor humedad. Según lo reglamentado, la panela debe ser empacada en hojas de cartón corrugado y deben contener en su etiqueta código de barras que identifique al producto, en los casos estudiados no se cumple con los protocolos de identificación exigidos en el mercado.

El evitar que la panela tenga contacto con animales y con superficies inadecuadas es una opción que permite reducir la contaminación microbiológica de la panela. Sin embargo, en los dos trapiches se permite que los animales tengan contacto con el alimento siendo estos una fuente de contaminación.

Por otra parte, así como la infraestructura de los trapiches es importante para la producción de panela, también son fundamentales sus alrededores porque allí también se pueden encontrar posibles fuentes de contaminación. En este estudio se encontró que cerca al trapiche San Francisco otras fincas estaban usando productos de abono inadecuados, lo que generaban presencia de moscas en este establecimiento, contaminando las superficies, implementos y la panela misma.

Por otro lado, hoy en día la preocupación de la industria alimentaria radica principalmente en el hecho de ofrecer alimentos seguros para el consumidor, que cuenten con procesos de producción garantizados. Sin embargo, es importante resaltar que la falta de formación y capacitación de los trabajadores y administradores de los establecimientos que producen alimentos es la causa principal de la obtención de productos de baja calidad que pueden generar riesgos para la salud y bienestar de la población. De esta forma, es necesaria la permanente capacitación en BPM.

Así mismo, es importante resaltar el escaso interés de las organizaciones que controlan la agroindustria panelera en implementar soluciones de mejoramiento en este campo, que permita a la panela convertirse en un producto competitivo en el mercado nacional e internacional y que sea del todo seguro para los consumidores.

La falta de difusión y conocimiento de las normas, protocolos de procedimientos y prácticas higiénicas sanitarias hacen que hoy en día la panela se considere un producto de poca calidad. En el análisis microbiológico se aislaron bacterias y hongos contaminantes. Los tipos de contaminación que se pueden presentar en la panela y la identificación de las fallas en el proceso de producción es el 
primer paso para comenzar a reducir la contaminación en este producto. Teniendo en cuenta que en el caso de las bacterias solamente el Leuconostoc mesenteroides hace parte de la flora normal de este alimento y las demás especies bacterianas encontradas provienen de hábitats diferentes.

A pesar de que el reporte de casos por intoxicación con panela no es muy alto ,es importante señalar que en este estudio se aislaron microrganismos que en otros escenarios son clínicamente significativos. El aislamiento de varias especies de Bacillus spp. plantea dos posibilidades: la primera como un agente que se relaciona con la producción de intoxicación alimentaria, debido a que en su proceso de esporulación libera toxinas (9), o la segunda como un agente biocontrolador ya que en las muestras de panela donde se aisló Bacillus spp., no se aisló ningún tipo de hongo. Este hallazgo ha sido confirmado por otros estudios; como el de Rodríguez, et al, en el cual se reporta que bacterias de los géneros Bacillus spp. y Pseudomonas spp, restringen efectivamente el crecimiento de hongos (10).

De la misma forma, el Centro de Investigaciones Agronómicas de la Universidad de Costa Rica utiliza Bacillus subtilis para proteger los cultivos de papa, chile dulce, café, tabaco, piña, tomate, melón, soya, camote, hortalizas, ornamentales, flores, cítricos, frente a plagas como: Rhizoctonia spp., Pythium spp., Fusarium spp., Erwinia spp (11). En argentina Reynaldi et al, reportan que bacterias como Bacillus megaterium y Bacillus cereus como biocontroladores, del crecimiento de Ascosphaera apis que afecta exclusivamente las larvas de las abejas (12).

El género Bacillus spp es una de las especies más comúnmente aisladas en el jugo de la caña de azúcar junto con Aerobacter aerogens, Actinomyces sp, Saccharomyces sp, Penicillium sp, Mucor sp y Aspergillus $s p$ (13), que en algunas ocasiones pueden inhibirse durante el proceso de producción. Sin embargo, cuando las temperaturas usadas no son las adecuadas o el microorganismo posee mecanismos de resistencia a condiciones ambientales adversas, se observa persistencia de estos agentes microbianos. También de observa que la etapa de empaque de la panela es la que más genera contaminación de tipo ambiental con hongos y levaduras osmofílicas que pueden deteriorarla.

De la misma forma existen bacterias que pueden llegar a ser benéficas para los alimentos como el Lactoccocus lactis $s p p$ cremoris, cuya presencia permite mantener la acidez de los alimentos. Así mismo, se obtuvieron bacterias que se reportan como productoras de sustancias antimicrobianas (bacteriocinas) que se han utilizado para la preservación de alimentos principalmente en productos lácteos y con alto contenido de azúcar como el Leuconostoc mesenteroides, inhibiendo el crecimiento de Clostridium spp y Staphylococcus aureus, con su bacteriocina, mesenterocina, la cual puede servir también como biocontroladora (14).

Sin embargo, dicha bacteria representa un riesgo para la industria panelera ya que al producir un polisacárido denominado dextrana, a partir de la sacarosa de la panela, retarda la cristalización y rendimiento de este carbohidrato y aumenta la viscosidad del jugo lo cual representa una disminución en la calidad del producto $(15,16)$.

Por otro lado, el desarrollar otras actividades agropecuarias como la cría de animales se genera contaminación, lo cual se refleja en el hallazgo de bacterias como Streptococcus uberis y Corynebacterium $s p p$, reportados en animales que padecen infecciones como mastitits bovina (17).

Dentro de los hallazgos de esta investigación y por primera vez reportada, se encontró Gardnerella vaginalis en los dos trapiches. Esta situación debe ser un motivo de preocupación con relación a la práctica de medidas higiénicas y sanitarias por parte de los trabajadores. Esta bacteria se aloja en la uretra del hombre y hace parte de la flora normal de la vagina, también se encuentra en ano y recto de los hombres y los niños. Esta bacteria es conocida por 
producir vaginosis bacteriana, septicemias posparto, endocarditis, infecciones del recién nacido, abscesos vaginales, bartolinitis, infecciones urinarias, abscesos hepáticos y de la orofarínge (18). De acuerdo con estudios se ha determinado que el poder patógeno del microorganismo se relaciona con una toxina citotóxica que rompe las células epiteliales y que a su vez induce la presencia de anticuerpos de tipo IgA como respuesta inflamatoria local (19). La presencia de este microorganismo se relaciona directamente con la implementación de las normas higiénicas de los trabajadores, ya que esta bacteria por sus sitios de alojamiento naturales, refleja el inadecuado lavado de manos por parte de los manipuladores de alimentos. En general la flora residente de las manos se encuentra conformada por Staphylococcus coagulasa negativa y por Difteroides, mientras que en la flora transitoria se pueden encontrar bacterias coliformes y en ocasiones Staphylococcus meticilino resistente, pero no es habitual encontrar bacterias como la Gardnerella vaginalis. Así mismo, cabe resaltar que aunque esta bacteria es de difícil crecimiento, sus propiedades fermentadoras le permiten extraer los nutrientes necesarios de la panela para su crecimiento.

Finalmente, es importante señalar la importancia de generar productos higiénicamente seguros y esto solo se logra con la aplicación de las BPM al disminuir al máximo el riesgo de contaminación de los productos (8), pero no es posible que los trabajadores las implementen si no las conocen y es ahí donde las personas y entidades encargadas deben realizar capacitaciones a todo el personal que labore en los trapiches y realizar evaluaciones periódicas del cumplimiento de las mismas.

\section{Referencias}

1. Rangel M. Estudio de Caracterización Ocupacional del Subsector de la Panela, con énfasis en los entornos Tecnológico y Ocupacional, como primer insumo para la Normalización por Competencias Laborales, de las diferentes áreas de desempeño de los procesos productivos y de exportación de la panela en sus diferentes presentaciones. Sogamoso: Servicio Nacional de Aprendizaje (SENA) Regional Boyacá; 2006.
2. Restrepo C. Historia de la panela colombiana, su elaboración y propiedades. [en línea] 2007: 1-6 [fecha de acceso 18 de octubre de 2012]. Disponible en: http://www.panelamonitor.org/ media/docrepo/document/files/historia-de-la-panela-colombiana-su-elaboracion-y-propiedades.pdf

3. Colombia. Ministerio de Agricultura y Desarrollo Rural. Decreto 1774 de 2004 por el cual se crea la Comisión Nacional Intersectorial para la Vigilancia de la Calidad de la Panela (Junio 2 del 2004).

4. Secretaría Distrital de Salud de Bogotá. Calidad Fisicoquímica - panelas año 2006. [en línea] 2006 [fecha de acceso 25 de febrero de 2012]. Disponible en: https://docs.google.com/vi ewer? $\mathrm{a}=\mathrm{v} \& \mathrm{q}=$ cache:CcHkWZiQXeAJ:190.25.230.149:8080/ dspace/bitstream/123456789/204/1/CALIDAD\%25 20FISICOQUIMICA \% 2520PANELAS\% 25202006. pdf+CALIDAD+FISIcoQUIMICA+-+PANELAS

5. Pujol V, Díaz J, Rodriguez E, et al. Contaminación microbiológica y actividad antimicrobiana del azúcar de caña cristalizada sobre algunos agentes de interés médico en Costa Rica. Revista de Biología Tropical [en línea] junio 2008: 433 - 435 [fecha de acceso 21 de febrero de 2012]. Disponible en: http:// www.latindex.ucr.ac.cr/rbt009-02.php.

6. Flores M. Proyecto de prefactibilidad para la exportación de panela al Canandá 2005-2015 [proyecto de grado Ingeniero de Comercio exterior e integración]. Quito (Ecuador). Universidad Tecnológica Equinoccial. Facultad de Ciencias Económicas y Negocios; 2005.

7. Gobernación del Atlántico. Plan de desarrollo departamental 2008 - 2011. [en línea] 2008; 1 - 182 [fecha de acceso 21 de febrero de 2012]. Disponible en: http://www.tubara-atlantico. gov.co/apc-aa-files/33363363663763646464326232363333/ plan de desarrollo departamental.pdf

8. Gobernación de Antioquia, Osorio G. Manual técnico de buenas prácticas agrícolas (BPA) y buenas prácticas de manufactura (BPM) en la producción de cańa y panela. [en línea] 2007; 142 - 145 [fecha de acceso 21 de febrero de 2012]. Disponible en: http://www.fao.org.co/manualpanela.pdf

9. Pérez Portuondo,I. Bacillus cereus y su papel en las intoxicaciones Alimentarias. Bacillus cereus and food poisoning. Revista Cubana de Salud Pública.[en línea] 2012: 98 - 108 [fecha de acceso 20 de enero de 2013] Disponible en: www.scielo.com

10. Rodríguez Amézquita J; Velandia Monsalve J, Viteri Rosero s. Evaluación de Microorganismos Aislados de Gallinaza por su Potencial para el Biocontrol de Fusarium (F. oxysporum) en Plántulas de Uchuva (Physalis peruviana), Rev.Fac.Nal.Agr. Medellín. .[en línea] 2010: 5499 - 5509 [fecha de acceso 20 de enero de 2013]. Disponible en: http://www.scielosp.org/pdf/ rcsp/v38n1/spu10112.pdf

11. Centro de investigaciones agronómicas, Universidad de Costa Rica boletín: biocontroladores [online],pp. 1-19 Disponible en: http://www.cia.ucr.ac.cr/pdf/BOLETIN UCR 2010.pdf

12. Reynaldi, f. J.; de giusti, m. R. Y alippi, a. M.. Inhibition of the growth of Ascosphaera apis by Bacillus and Paenibacillus strains isolated from honey. Rev. argent. microbiol. [online]. 2004, vol.36, n.1 [citado 13-01-2013], pp. 52-55 . Disponible en: http://www.scielo.org.ar/scielo.php?script=sci $\underline{\text { arttext\&pid }=\text { S0325-75412004000100011\&lng=es\&nrm=iso }}$ 
13. Singh S.Dubey A,tiwari L, et al. Microbial profile of stored jaggery: a traditional indian sweetener, sugar tech. [en línea] 2009: 213 - 216 [fecha de acceso 18 de febrero de 2013]. Disponible en: http://scienceindex.com/stories/311085/Microbial profile of stored jaggery A traditional Indian sweetener.html

14. Parra Huertas R. Bacterias acido lácticas: papel funcional en los alimentos. Facultad de ciencias agropecuarias. [en línea] 2010: 94 - 105 [fecha de acceso 4 de febrero de 2013]. Disponible en: http://www.scielo.org.co/scielo.php?pid=S1692$\underline{35612010000100012 \& \text { script=sciarttext }}$

15. López D, Zavala R. Análisis Socioeconómico del subsector Panelero de los Departamentos: Cabañas, Cuscatlán, La Paz y San Vicente. [proyecto de grado Ingeniero Agrónomo]. San Salvador: Universidad de El Salvador. Facultad de Ciencias Agronómicas; 2010.

16. Rodríguez E. La dextranasa a lo largo de la Industria azucarera. Biotecnología aplicada [en línea] La Habana (Cuba); 2005:
11- 19 [fecha de acceso 4 de febrero de 2013]. Disponible en:http://elfosscientiae.cigb.edu.cu/PDFs/BA/2005/22/1/ BA002201OR011-019.pdf

17. Zadoks R, Allore H, Barkema H, et al. Analysis of an outbreak os Streptococcus uberis mastitis. Journal of Dairy Science. New York (USA); 200: 133 - 154 [fecha de acceso 4 de febrero de 2013]. Disponible en: http://igitur-archive.library.uu.nl/ dissertations/2003-0205-114913/c6.pdf

18. Centro de investigaciones agronómicas, universidad de costa rica boletín: biocontroladores [online],pp. 1-19 Disponible en: http://www.cia.ucr.ac.cr/pdf/BOLETIN UCR 2010.pdf

19. Sánchez J, Coyotecatl L, Valentín E, et al. Diagnóstico clínco, de laboratorio y tratamiento de la vaginosis por Gardnerella vaginalis. Universitas médica. México; 2007: 382 - 395 [fecha de acceso 4 de febrero de 2013]. Disponible en: http:// med.javeriana.edu.co/publi/vniversitas/serial/v48n4/5-VAGINOSIS.pdf 